\title{
Impact of a Mobile App on Paramedics' Perceived and Physiologic Stress Response During Simulated Prehospital Pediatric Cardiopulmonary Resuscitation: Study Nested Within a Multicenter Randomized Controlled Trial
}

Matthieu Lacour ${ }^{1}$, MMed; Laurie Bloudeau², EMT-P; Christophe Combescure ${ }^{1,3}, \mathrm{PhD}$; Kevin Haddad ${ }^{4}$, RNCS; Florence Hugon ${ }^{4}$, RNCS; Laurent Suppan ${ }^{1,5}$, MD; Frédérique Rodieux ${ }^{1,6}$, MD; Christian Lovis ${ }^{1,7}$, MPH, MD; Alain Gervaix $^{1,4}$, MD; Frédéric Ehrler ${ }^{1,7}$, PhD; Sergio Manzano ${ }^{1,4}$, MD; Johan N Siebert ${ }^{1,4}$, MD; PedAMINES Prehospital Group $^{8}$

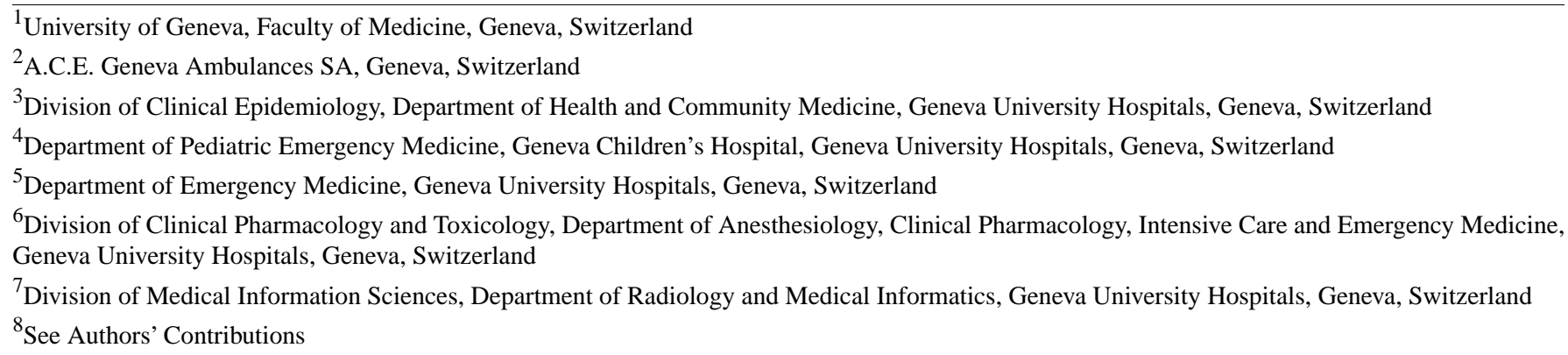

\section{Corresponding Author:}

Johan N Siebert, MD

Department of Pediatric Emergency Medicine, Geneva Children's Hospital

Geneva University Hospitals

Avenue de la Roseraie, 47

Geneva, 1205

Switzerland

Phone: 41 (0)795534072

Fax: 41 (0)223725405

Email: Johan.Siebert@hcuge.ch

\begin{abstract}
Background: Out-of-hospital cardiac arrests (OHCAs) are stressful, high-stake events that are associated with low survival rates. Acute stress experienced in this situation is associated with lower cardiopulmonary resuscitation performance in calculating drug dosages by emergency medical services. Children are particularly vulnerable to such errors. To date, no app has been validated to specifically support emergency drug preparation by paramedics through reducing the stress level of this procedure and medication errors.

Objective: This study aims to determine the effectiveness of an evidence-based mobile app compared with that of the conventional preparation methods in reducing acute stress in paramedics at the psychological and physiological levels while safely preparing emergency drugs during simulated pediatric OHCA scenarios.

Methods: In a parent, multicenter, randomized controlled trial of 14 emergency medical services, perceived and physiologic stress of advanced paramedics with drug preparation autonomy was assessed during a 20-minute, standardized, fully video-recorded, and highly realistic pediatric OHCA scenario in an 18-month-old child. The primary outcome was participants' self-reported psychological stress perceived during sequential preparations of 4 intravenous emergency drugs (epinephrine, midazolam, 10\% dextrose, and sodium bicarbonate) with the support of the PedAMINES (Pediatric Accurate Medication in Emergency Situations) app designed to help pediatric drug preparation (intervention) or conventional methods (control). The State-Trait Anxiety Inventory and Visual Analog Scale questionnaires were used to measure perceived stress. The secondary outcome was physiologic stress, measured by a single continuous measurement of the participants' heart rate with optical photoplethysmography.
\end{abstract}


Results: From September 3, 2019, to January 21, 2020, 150 advanced paramedics underwent randomization. A total of 74 participants were assigned to the mobile app (intervention group), and 76 did not use the app (control group). A total of 600 drug doses were prepared. Higher State-Trait Anxiety Inventory-perceived stress increase from baseline was observed during the scenario using the conventional methods (mean 35.4, SD 8.2 to mean 49.8, SD 13.2; a 41.3\%, 35.0 increase) than when using the app (mean 36.1, SD 8.1 to mean 39.0, SD 8.4; a 12.3\%, 29.0 increase). This revealed a 30.1\% (95\% CI 20.5\%-39.8\%; $P<.001)$ lower relative change in stress response in participants who used the app. On the Visual Analog Scale questionnaire, participants in the control group reported a higher increase in stress at the peak of the scenario (mean 7.1, SD 1.8 vs mean 6.4, SD 1.9; difference: $-0.8,95 \% \mathrm{CI}-1.3$ to $-0.2 ; P=.005)$. Increase in heart rate during the scenario and over the 4 drugs was not different between the 2 groups.

Conclusions: Compared with the conventional method, dedicated mobile apps can reduce acute perceived stress during the preparation of emergency drugs in the prehospital setting during critical situations. These findings can help advance the development and evaluation of mobile apps for OHCA management and should be encouraged.

Trial Registration: ClinicalTrials.gov NCT03921346; https://clinicaltrials.gov/ct2/show/NCT03921346

International Registered Report Identifier (IRRID)： RR2-10.1186/s13063-019-3726-4

(JMIR Mhealth Uhealth 2021;9(10):e31748) doi: 10.2196/31748

\section{KEYWORDS}

cardiopulmonary resuscitation; drugs; emergency medical services; medication errors; mobile health; mobile apps; out-of-hospital cardiac arrest; paramedics; pediatrics; State-Trait Anxiety Inventory; stress

\section{Introduction}

\section{Background}

Out-of-hospital cardiac arrest (OHCA) is a major concern for health care systems worldwide, affecting millions of people each year [1]. Despite advances in resuscitation science and improvement of cardiac arrest survival over the past decades, the survival rates following adult and pediatric OHCA are reportedly low, evaluated at $10.4 \%$ and $11.4 \%$, respectively [1]. High-quality cardiopulmonary resuscitation (CPR) for OHCA patients is the primary determinant of survival and favorable neurological outcome [2,3]. Evaluations and decisions must be made quickly and accurately. However, acute mental stress experienced by rescuers during CPR may impair decision making and optimal performance [4-12], independent of professional experience [4]. This can, in turn, adversely affect patient safety [5]. OHCA-induced acute stress response relies mainly on an interplay between the individual's cognitive perception and appraisal made about the perceived demand and ability to compensate through both internal and environmental resources $[6,13]$. The degree to which this compensation occurs determines the nature and magnitude of one's stress response [12]. Some individuals show stress responses with associated active coping. Others perceive stress as excessive and outweighing their coping abilities, thus hindering their ability to adapt quickly and perform under pressure.

The OHCA setting is a stressful and high-stakes environment where safeguards and resources, both human and material, are limited [6]. In many countries, paramedics have the autonomy to prepare and administer emergency drugs. However, the impact of acute stress experienced by paramedics during OHCA on emergency drug preparation has rarely been studied. LeBlanc et al [14] observed that paramedics under simulated high-stress conditions performed worse on drug dosage calculations than those under calm, relaxed conditions. These findings are particularly concerning in pediatric $\mathrm{CPR}$, where the accurate and safe preparation and administration of intravenous drugs is mandatory [15-19]. Most drugs administered intravenously to children are provided in vials that were originally prepared for the adult population. This leads to the need for an initial onsite complicated, individual, weight-based dose calculation, and drug preparation for each child, which varies widely across age groups [20]. Combined with other risk factors such as excessive extraneous cognitive load due to onsite emotional stress and time pressure [14,21-23], and pediatric-specific, age-related variations in pharmacokinetics, onsite administration of emergency drugs by paramedics is particularly challenging. Furthermore, pediatric situations only account for approximately $7 \%$ of emergency medical services (EMS) calls, and paramedics have little exposure to critically ill children and occasions to prepare emergency drugs at pediatric dosages [24-26]. Relying solely on their expertise and knowledge to take decisions during care provision, a single paramedic is often in charge of determining the child's weight, choosing the most suitable drug, calculating the drug dose and appropriate volume to inject, and administering it without delay. For this purpose, paramedics are still dependent on conventional paper-based support, empirical calculators, or spreadsheets to ensure correct drug delivery. This places children at higher risk for life-threatening prehospital medication errors than adults [17,20,27-30], with a reported error rate of more than $60 \%[31,32]$.

Some authors have advocated replacing tasks inducing stress and cognitive load during resuscitation as much as possible by automated actions to optimize patient care and diminish medication errors [22,33]. The US National Highway Traffic Safety Administration advocated, in its recent vision for the future of pediatric prehospital care to be achieved by 2050, to develop processes that do not require providers to calculate dosing of medications [34]. Supported by the rapid spread of mobile devices and their innovative features (eg, connectivity, embedded computing capabilities, small size, and versatility), mobile health (mHealth) apps have great potential as tools to support out-of-hospital emergency drug preparation at the point 
of care. However, a recent systematic review showed that few mHealth apps are available for prehospital settings [35]. Among these mHealth apps, none has been validated to specifically support emergency drug preparation by EMS personnel with the aim of reducing medication dosing errors and the stress hassle of this procedure.

\section{Previous Work}

In previous randomized trials, we reported fewer medication errors and shorter times to drug preparation and delivery during in-hospital pediatric CPR when using a mobile app-the PedAMINES (Pediatric Accurate Medication in Emergency Situations) app compared with conventional preparation methods [36,37]. Although similarities exist, the prehospital environment is distinctly different in many regards. Recent findings of a multicenter randomized trial showed that this app was also able to reduce medication error rates during pediatrics OHCA in a simulated model [38]. However, its impact on situational stress experienced by paramedics during CPR remains to be determined.

\section{Aim}

This study aims to determine the effectiveness of the PedAMINES app in reducing acute stress while safely preparing emergency drugs during CPR for pediatric OHCA patients compared with the conventional preparation methods.

\section{Methods}

\section{Study Design}

This study was registered at ClinicalTrials.gov (NCT03921346) as a nested study within the context of an open-label, multicenter, randomized controlled trial. The parent trial had the broader and primary aim of assessing rates of medication dosing errors during simulation-based pediatric OHCA scenarios using a high-fidelity manikin [38]. The trial protocol, containing details about the scenario, has been previously published [39]. No changes were made to the app or intervention during the study.

\section{Trial Participants}

The trial was conducted at 14 EMS covering a population of more than 2.3 million people in Switzerland. Eligible participants were registered paramedics working in these EMS. They had undergone a 3-year education program and were trained in advanced life support procedures, including defibrillation, airway management, peripheral intravenous line cannulation, and the administration of medications to ensure advanced independent emergency prehospital care. Similar to the Anglo-American model [40,41], paramedics in Switzerland constitute the initial response team and are qualified to independently administer a range of medications. To achieve adequate participant enrolment to reach the target sample size (ie, 120 paramedics [39]), shift-working paramedics were randomly recruited weeks before the start of the study by a blinded noninvestigator in each EMS center. In several EMS centers, additional paramedics were recruited to ensure that the target sample size would ultimately be achieved. At the end of the trial, an additional number of paramedics was included in the study and the analysis was refined. To prevent preparation bias, all paramedics were informed of the upcoming simulation study, but not of its purpose and outcomes. The study excluded emergency medical technicians because they had no drug preparation autonomy. In our study, resuscitation was led by a physician (JNS) to standardize the choice of drugs prescribed across the EMS and to avoid any deviation from the study protocol. Written informed consent was obtained from all the participants before their voluntary involvement. Blinding to the purpose of the trial during recruitment was maintained to minimize preparation bias. Participants were unblinded during the intervention when they were asked to prepare the drugs either with the support of the app or conventional methods. Study participants were neither involved in the design of the app, study design, choice of outcome measures, nor study conduct. No participant was asked to advice on the interpretation or write the results.

\section{Setting}

The trial took place in a simulated, regular child's bedroom environment at each EMS center. This was intended to mimic as closely as possible a stressful prehospital environment where paramedics could actually intervene to increase realism. The intervention was standardized across all sites to follow the same chronological progression and range of difficulty in order to ensure that each participant was exposed to exactly the same situation, with similar challenges in decision making and treatment preparation provided on the same manikin (Laerdal New SimBaby, Tetherless, Laerdal Medical, Stavanger, Norway). The study team members maintained a stressful resuscitation atmosphere. Importantly, we did not organize pretests to minimize priming and preparation biases to avoid influencing the perceived stress during the scenario.

\section{Intervention}

On the day of the participation after random allocation, each participating paramedic had to complete 2 self-administered questionnaires to measure their perceived stress at baseline (see below), and a heart rate (HR) monitor was placed on their wrist. They also had to complete a survey collecting data regarding their demographics, attend a standardized 5-minute training session on how to use the mobile app, and follow a presentation detailing the features of the simulation manikin. No conventional drug preparation training was provided in either group, as this was part of the paramedics' daily practice. Each participant was then exposed to a 20-minute, standardized, fully video-recorded, highly realistic pediatric OHCA CPR scenario of an 18-month-old child. The participants were asked to sequentially prepare and inject 4 different direct intravenous drugs of various degrees of preparation difficulties (epinephrine, midazolam, dextrose $10 \%$, and sodium bicarbonate), either with the support of the app or following conventional methods (ie, without app support). Full details of the intervention and scenario have been previously published [38]. During the timed scenario, the resuscitation team maintained a stressful and realistic resuscitation atmosphere by frequently reporting vital signs aloud and asking the participant to promptly provide the drugs. The portable defibrillator, displaying real time vital signs, was placed in close proximity to the paramedics. The monitoring 
alarms were turned on, and the investigator who played the father's role repeatedly verbalized his dismay.

\section{The PedAMINES Mobile App}

This app provided an exhaustive and editable list of intravenous drugs, either for direct injections or continuous infusions $[37,38,42]$. The drugs were displayed in alphabetical order with doses automatically adapted to the weight or age of the patient. When selected, a detailed drug preparation procedure based on a standardized and simplified pathway was provided to the user. The app was developed using a user-centered, evidence-based approach. Emergency department caregivers, ergonomists, psychologists, and computer scientists from research and development services conceived the app. Its interface was designed considering design principles aimed at minimizing cognitive load [43-45]. By always displaying the most important information in a larger font and sorting the most recent information at the top of the screen, hierarchization of information was taken into consideration. Interaction choices were limited to their strictest utility through the interface to facilitate decision making. Only a predefined sequence of actions was proposed; thus, users did not need to make complicated choices. Display conventions were defined to display drug dosages with conventional and consistent units to avoid confusion. Fits laws were complied with by placing interaction buttons at the edge of the screen [46]. This minimized the distance to reach them and focused on the interaction zone in a limited area. The app also complied with the progressive disclosure principle [47], where complex information is sequenced across several smaller chunks to reduce the feeling of being overwhelmed by the user. Therefore, complex instructions such as weight-based drug dose preparation was sequenced and ordered in several lines to streamline information and facilitate its comprehension (Figure 1). Feedback mechanisms have also been integrated for specific actions, such as canceling or modifying the patient's weight. In both cases, the system provides feedback to ensure that users are aware of their actions. Acceptance and use of the app were assessed through self-administrated electronic surveys using a modified version of the Unified Theory of Acceptance and Use of Technology (UTAUT) model [48] and the System Usability Scale $[49,50]$. They will be the subject of detailed analysis in another study nested within the parent trial.

Figure 1. PedAMINES (Pediatric Accurate Medication in Emergency Situations) app screenshot.

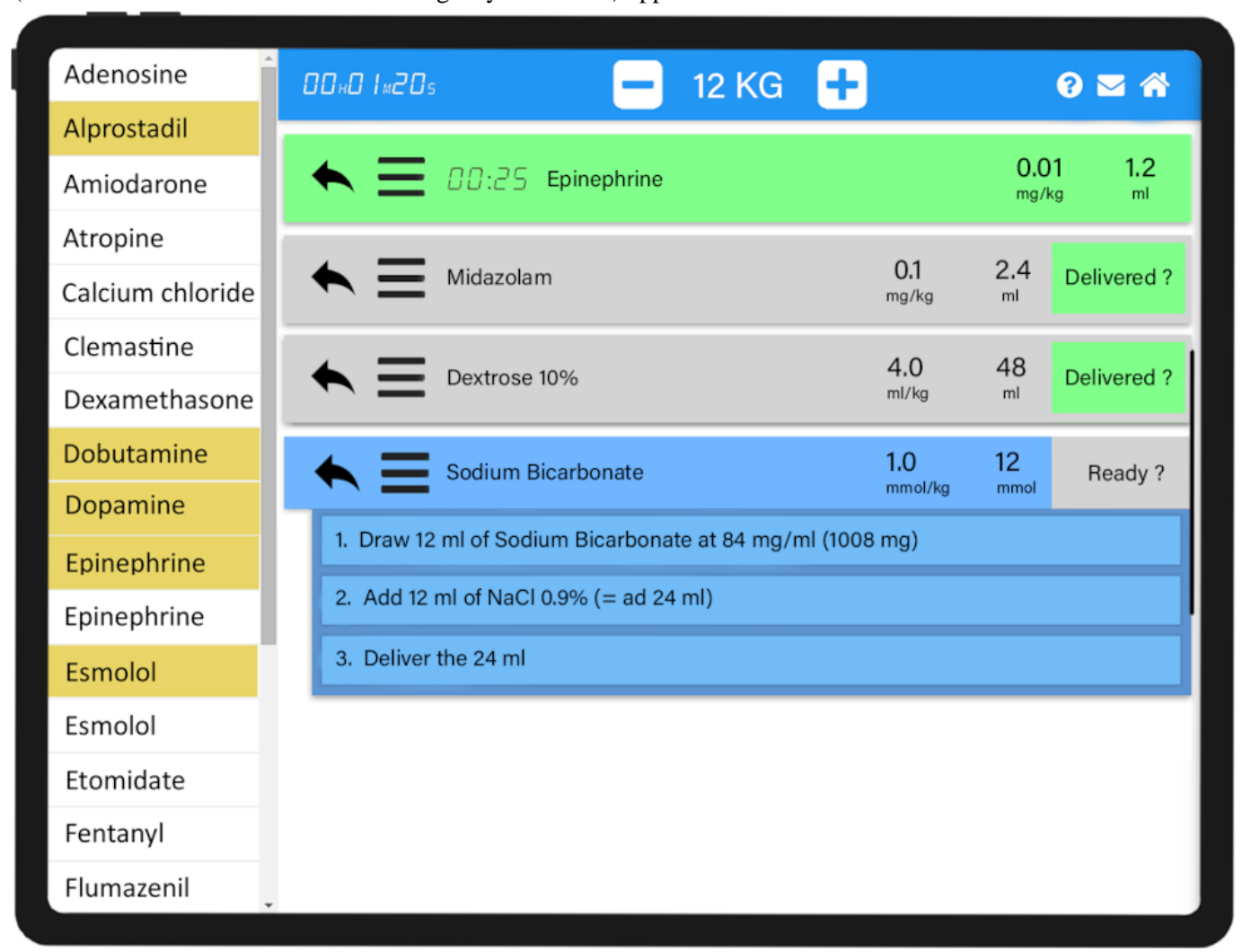

\section{Outcomes and Measures}

\section{Primary Outcome: Perceived Stress}

Participants' self-assessed psychological stress was measured using the Gauthier and Bouchard's French-Canadian adaptation [51] of Spielberger's psychometric State-Trait Anxiety Inventory (STAI) questionnaire [52,53]. STAI was provided with permission from the copyright owner (Mind Garden, Inc [54]. Copyright prevents reproduction of the full scale). It is one of the most commonly used subjective measures of stress in health research, including emergency care [13,14,55-58]. This questionnaire is composed of two 20-item self-report subscales to measure 2 distinct anxiety concepts: (1) the temporary state of anxiety at the time of reporting (STAI form Y-1), which can be affected by stressful situations and 2) the more stable and long-standing presence of trait anxiety (form Y-2) [59]. Both forms can be used alone or as a complement. Form Y-1 was used in this study. To avoid interrupting the scenario and influence its veracity and inherent stress, no STAI was 
administered during the scenario. It was administered just before the scenario began to assess the stress at this moment, and again just after the end of the scenario by asking the paramedics to assess their maximum perceived stress during the scenario (Figure 2). Each item was mandatory to avoid missing values and answered on a 4-point Likert scale ranging from 1 (not at all) to 4 (very much). After reversing the scores for stress-absent items (ie, items 1, 2, 5, 8, 10, 11, 15, 16, 19, and 20) according to Spielberger's instructions [59], the total score was calculated by summing up the weighted scores for the 20 items. STAI ranges from 20 to 80 , with higher scores being positively correlated with greater stress [59]. A score greater than 40 is commonly used to define a clinical state of stress.
Perceived stress was also assessed by self-assessment using a numerical 10-point Likert visual analogue scale (VAS) [60]. Values ranged from 1 (totally unstressed) to 10 (totally stressed) to avoid neutral answers. To prevent any anticipation bias, participants were not informed that they would have to complete the STAI and VAS questionnaires after scenario completion (Figure 2). The questionnaires were provided onsite with the necessary precautions so that participants could not communicate with each other. No interaction other than detailing an item upon request of a participant occurred between the participants and investigators during the completion of the questionnaires.

Figure 2. Course of the intervention. CPR: cardiopulmonary resuscitation; HR: heart rate; pOHCA: pediatric out-of-hospital cardiac arrest; STAI: State-Trait Anxiety Inventory; VAS: visual analogue scale.

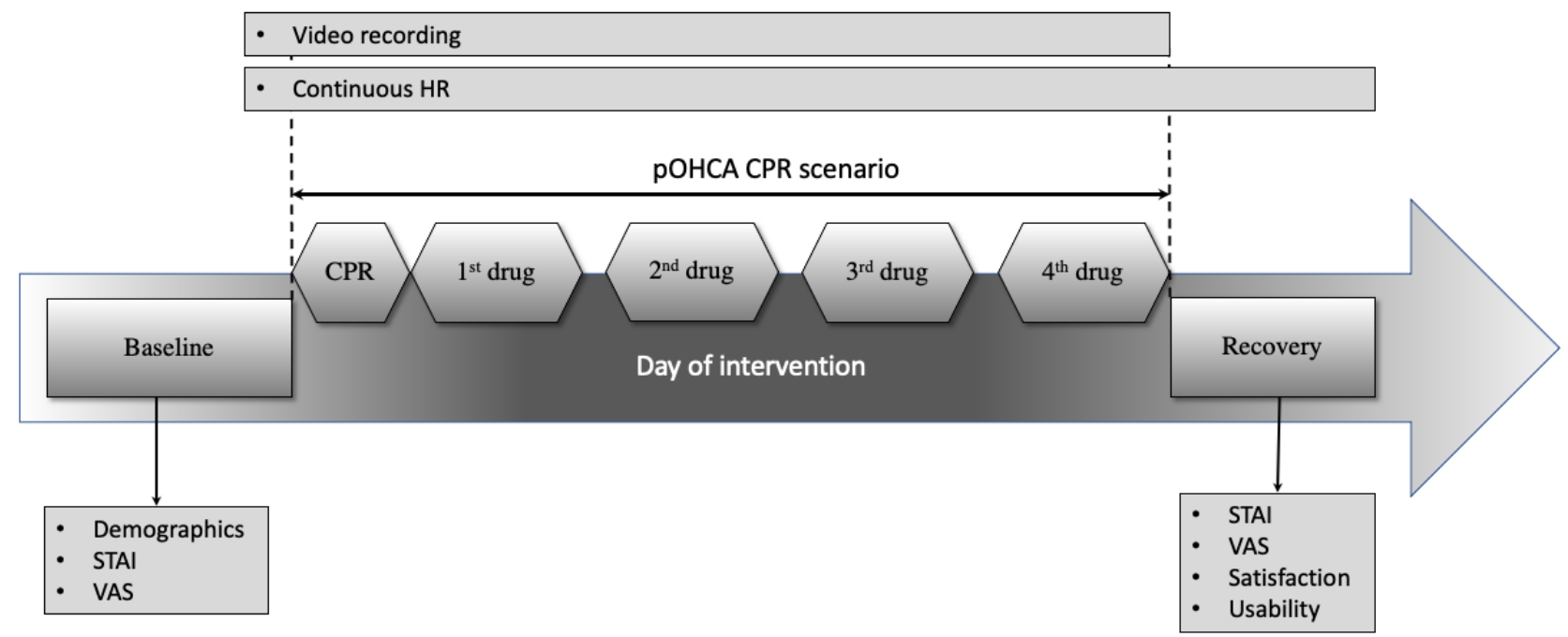

\section{Secondary Outcome: Physiologic Stress}

HR was measured as a surrogate of the physiological sympathetic response to stress [61]. A single continuous measurement at 1 -second interval was recorded during the scenario with optical photoplethysmography using a Polar A360 wrist-worn HR monitor (Polar Electro Oy). This wearable sensor has been previously validated for HR assessment [62,63], although it is not sensitive enough to track HR variability. The A360 was tightly attached to the participants' wrist in accordance with the manufacturer's specifications to avoid motion artifacts that could lead to inaccurate HR measurements. Data locally stored on the wristwatch itself during the scenarios was thereafter synchronized with the dedicated Polar FlowSync web service for later offline analysis. In line with previous research [64], several time-points of cardiovascular activity were measured: (1) the minimal HR measured within the 5 minutes before the scenario starts ( $\left.\mathrm{HR}_{\text {baseline }}\right)$ while participants were not performing mental or physical exercise; (2) peak HR $\left(\mathrm{HR}_{\text {peak }}\right)$ for each drug, defined as the maximal HR reached during the sequence from drug prescription by the physician to drug delivery; and (3) an additional $\mathrm{HR}_{\text {recovery }}$ was also measured as the minimal HR measured during the 5 minutes immediately following scenario completion (ie, at the stop of the timed period of the scenario represented by the patient's arousal, but before debriefing).

\section{Data Collection}

All scenarios were video-recorded by 3 GoPro Hero 5 and 7 Black Edition (GoPro Inc) video cameras mounted on participants and dispatched around them for later analysis. The camera setup was standardized. The investigators double-checked whether the questionnaires were fully and accurately completed. Data was collected using a REDCap database web app (REDCap, Vanderbilt University) hosted at Geneva University Hospitals and interfaced on an iPad Pro iOS 12.4 (Apple Inc). Neither follow up nor retention plans were required.

\section{Statistical Analysis}

Assuming a two-sided $\alpha$ risk of .05, the number of participants enrolled in the parent study was sufficient to detect an effect size of 0.50 , which corresponds to a medium effect of the app compared with the conventional methods on perceived stress (STAI-Y score), with a power of $80 \%$. Outcomes with a single measurement per participant (including $\mathrm{HR}_{\text {peak }}$ per drug and 
postintervention STAI-Y and VAS) were compared between trial arms by using linear regression models with adjustment for the preintervention or baseline value and on centers to account for the randomized stratification. To compare the overall $\mathrm{HR}_{\text {peak }}$ between the arms, a linear regression model with mixed effects and adjusted for centers and $\mathrm{HR}_{\text {baseline was used to }}$ account for the multiple measures per participant (one per drug). With this model, the intercept was random with crossed random effects at the participant and drug levels. This model was adjusted for the centers and $\mathrm{HR}_{\text {baseline. The Spearman correlation }}$ coefficient was used to assess the correlation between outcomes. Analyses were carried out using $\mathrm{R}$ software version 4.0.2, and the R package lme4 [65]. All statistical tests were two-sided, with an $\alpha$ risk of .05 .

\section{Ethics Approval}

This trial received a declaration of no objection by the Geneva Cantonal Ethics Committee and Swiss Ethics on March 29, 2018, as its purpose was to examine the effect of the intervention on health care providers. The study was conducted in accordance with the principles of the Declaration of Helsinki [66], Good Clinical Practice guidelines [67], the Consolidated Standards of Reporting Trials of Electronic and Mobile Health Applications and Online TeleHealth (CONSORT-EHEALTH) [68] guidelines, and the Reporting Guidelines for Health Care Simulation Research [69].

\section{Results}

\section{Overview}

Of the 150 paramedics enrolled between September 3, 2019, and January 21, 2020, 74 were assigned to the intervention group and 76 to the control group. A total of 600 drug preparations were prepared. One participant's HR recording data were missing in the intervention group due to a technical problem with the watch. No dropouts occurred (Figure 3). The baseline characteristics are detailed in the published parent trial [38]. They were balanced in the 2 groups, and recruitment was balanced across the centers.

Figure 3. Screening, randomization, and analysis.

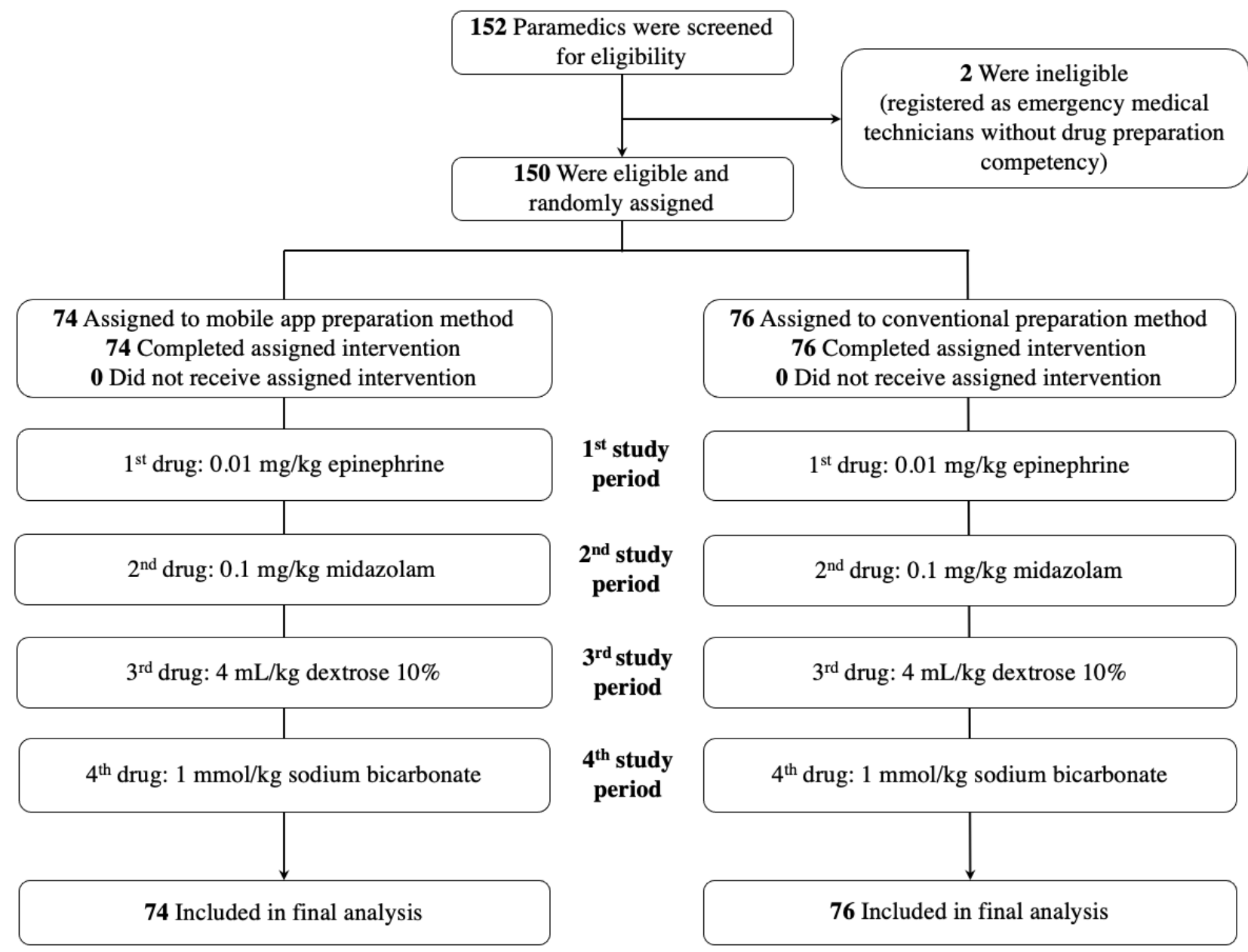

\section{Stress Response: Perceived Stress}

Both the STAI Form Y-1 and VAS questionnaires were completed by all 150 participants. Baseline STAI-perceived stress levels before the start of the scenario did not differ between the allocation groups (Table 1). The mean

STAI-perceived stress scores of the participants supported by conventional methods then increased significantly at the time of drug preparations, whereas no significant increase was observed with the app support during the scenario. A higher stress increase was observed during the scenario using the 
conventional methods than the app $(P<.001$; Table 1 and Figure 4).

Similarly, on the VAS questionnaire, participants rated the mean perceived stress before the scenario as not different with or without the app support (Table 1 and Figure 4). After scenario completion, they reported a higher increase in stress at the peak of the scenario using the conventional method than the app. The paramedics' gender, age, and years of experience did not modify the intervention effect, although for paramedics with more than 10 years of experience, the effect of the app seems to weaken (Multimedia Appendix 1).

Table 1. Comparison of STAI Form Y-1 and VAS scores before and after scenario completion $(\mathrm{N}=150)$.

\begin{tabular}{|c|c|c|c|c|}
\hline & Mobile app ( $\mathrm{n}=73)$, mean (SD) & Conventional method $(\mathrm{n}=76)$, mean (SD) & Difference $(95 \% \mathrm{CI})^{\mathrm{a}}$ & $P$ value \\
\hline \multicolumn{5}{|l|}{ STAI $^{\mathbf{b}}$} \\
\hline Preintervention & $36.1(8.1)$ & $35.4(8.2)$ & $0.8(-1.7$ to 3.3$)$ & .55 \\
\hline Postintervention & $39.0(8.4)$ & $49.8(13.2)$ & $-11.4(-14.7$ to -8.0$)$ & $<.001$ \\
\hline $\begin{array}{l}\text { Relative change (\% of } \\
\text { preintervention) }\end{array}$ & $12.3(29)$ & $43.1(35)$ & $-30.1(-39.8$ to -20.5$)$ & $<.001$ \\
\hline \multicolumn{5}{|l|}{$\mathbf{V A S}^{\mathrm{c}}$} \\
\hline Preintervention & $4.2(2.5)$ & $3.9(2.2)$ & $0.3(-0.4$ to 1.0$)$ & .35 \\
\hline Postintervention & $6.4(1.9)$ & $7.1(1.8)$ & $-0.8(-1.3$ to -0.2$)$ & .006 \\
\hline
\end{tabular}

${ }^{\mathrm{a}}$ Linear regression models adjusted for center; in addition, differences in postintervention and relative change were adjusted for the preintervention values.

${ }^{\mathrm{b}}$ STAI: State-Trait Anxiety Inventory.

${ }^{\mathrm{c}}$ VAS: visual analogue scale.

Figure 4. State-Trait Anxiety Inventory Form Y-1 and Visual Analogic Score box plots per study arm. PedAMINES: Pediatric Accurate Medication in Emergency Situations; STAI: State Trait Anxiety Inventory; VAS: visual analogue scale.

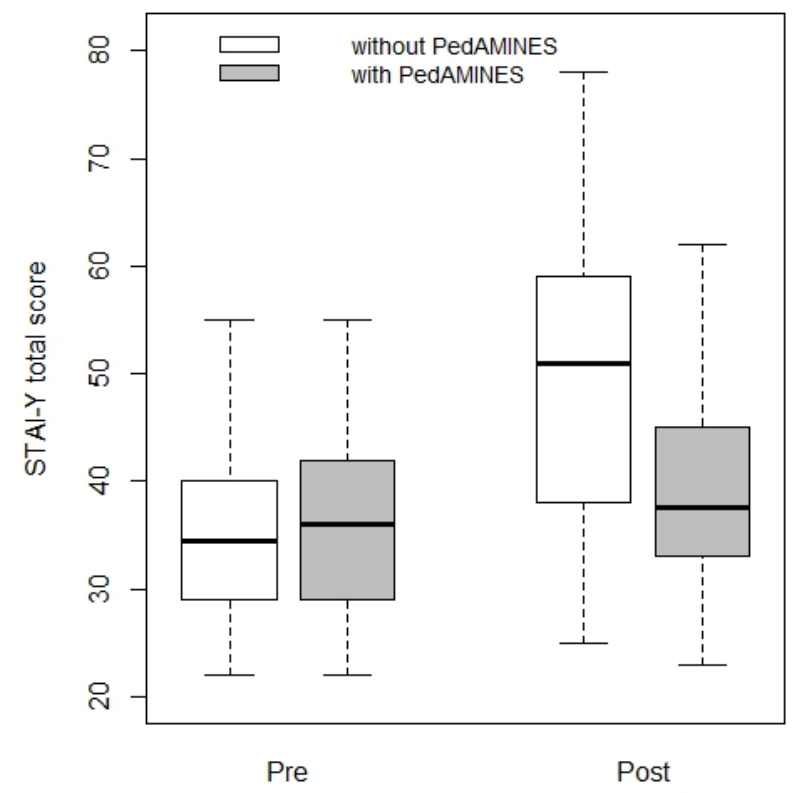

\section{Stress Response: Heart Rate}

The mean $\mathrm{HR}_{\text {baseline }}$ before the scenario started was approximately 80 beats per minute and similar between the allocation groups (Table 2). Maximal HR achieved during cardiac compressions was 122.5 (95\% CI 118-127) in the app

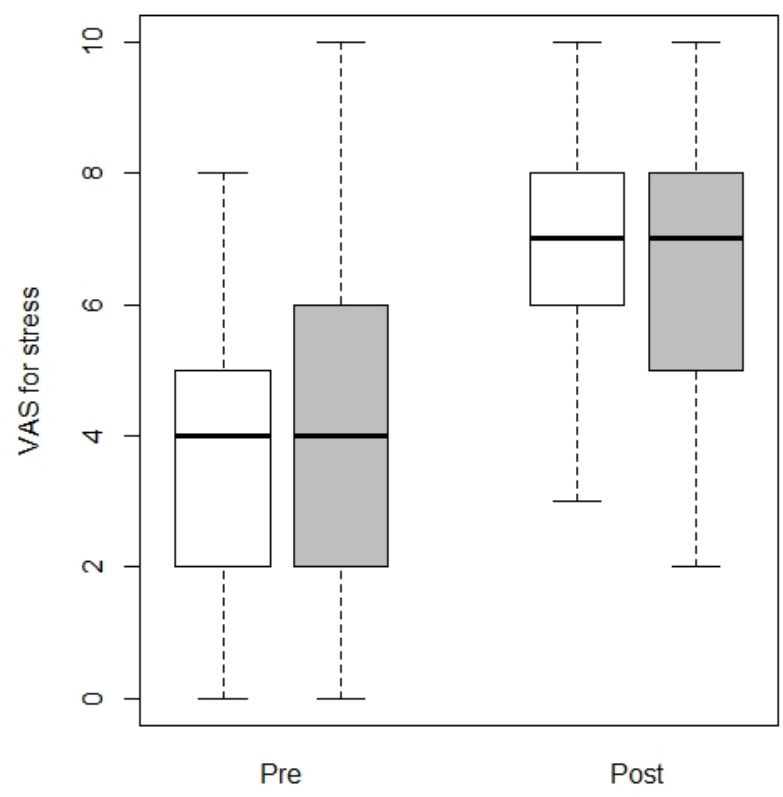

group and 123 (95\% CI 117-128) in the control group and decreased in both groups before the drug preparation phase. During the scenario, the overall $\mathrm{HR}_{\text {peaks }}$ for the 4 drugs increased to 118 (95\% CI 111 to 125 ) beats per minute with conventional methods and to 119.7 (95\% CI 115 to 124) beats per minute with the app. This increase in HR from baseline represented 


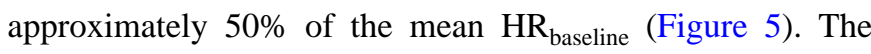
difference between groups in $\mathrm{HR}_{\text {peaks }}$ during the scenario and over the 4 drugs was $1.4(95 \% \mathrm{CI}-1.8$ to $4.6 ; P=.43)$ beats per minute, which was not statistically significant. The same was true for each drug (Table 2). After completion of the scenarios, $\mathrm{HR}$ declined to recovery values similar to $\mathrm{HR}_{\text {baseline }}$ in both groups.

Table 2. Heart rates before, during, and after scenario completion, per study group ( $\mathrm{N}=150)$.

\begin{tabular}{|c|c|c|c|c|}
\hline & \multicolumn{4}{|l|}{ Heart rate $\left(\mathrm{bpm}^{\mathrm{a}}\right)$} \\
\hline & Mobile app (n=73), mean (SD) & Conventional method $(\mathrm{n}=76)$, mean (SD) & Difference $(95 \% \mathrm{CI})^{\mathrm{b}}$ & $P$ value \\
\hline Baseline & $79.3(14.4)$ & $78.5(12.7)$ & $1.0(-3.3$ to 5.3$)$ & .64 \\
\hline First drug, $\mathrm{HR}_{\text {peak }}^{\mathrm{c}}$ & $123.1(9.2)$ & $124.1(12.2)$ & $-1.1(-4.7$ to 2.4$)$ & .53 \\
\hline Second drug, $\mathrm{HR}_{\text {peak }}$ & $121.1(10.9)$ & $119.9(13.3)$ & $1.0(-2.8$ to 4.8$)$ & .61 \\
\hline Third drug, $\mathrm{HR}_{\text {peak }}$ & $120.4(11.4)$ & $117.9(13.3)$ & $2.4(-1.4$ to 6.2$)$ & .22 \\
\hline Fourth drug, $\mathrm{HR}_{\text {peak }}$ & $114.1(13.5)$ & $110.5(13.7)$ & $3.4(-0.9$ to 7.6$)$ & .12 \\
\hline Recovery & $79.3(15.0)$ & $76.8(13.7)$ & $1.9(-2.3$ to 6.1$)$ & .37 \\
\hline Maximal $\mathrm{HR}_{\text {peak }}{ }^{\mathrm{d}}$ & $126.1(10.3)$ & $126.0(12.1)$ & $-0.1(-3.8$ to 3.5$)$ & .95 \\
\hline
\end{tabular}

${ }^{\mathrm{a}} \mathrm{bpm}$ : beats per minute.

${ }^{\mathrm{b}}$ Linear regression models adjusted for center and baseline heart rate using linear regression models (except for baseline heart rate adjusted for center only). A negative difference means that the average value is lower with than without PedAMINES.

${ }^{\mathrm{c}} \mathrm{HR}$ : heart rate.

${ }^{\mathrm{d}}$ Highest value of $\mathrm{HR}_{\text {peak }}$ among the 4 drugs.

Figure 5. Mean heart rate (error bars=SD) in the baseline, the 4 consecutive heart rate peaks numbered according to the sequential prescription of each drug, and recovery time points over the course of the scenario. HR: heart rate.

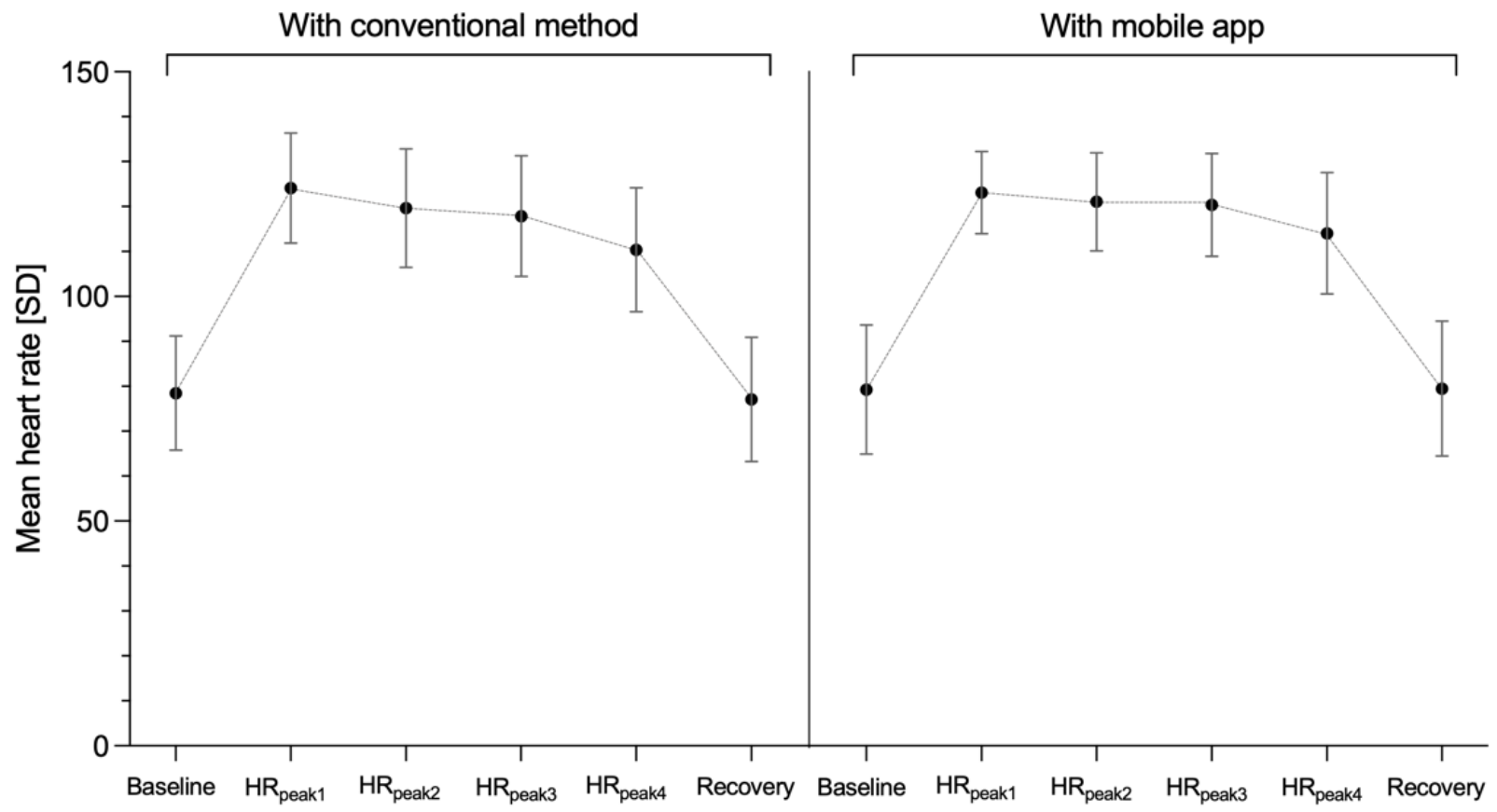

\section{Correlation Between Perceived Stress and Heart Rate}

A strong correlation was found between STAI-Y and the VAS scores for the perceived stress by the participants before the intervention (Spearman $r=0.72$ ) and after the intervention (Spearman $r=0.68$ ). However, the STAI-Y and the VAS scores before the intervention were poorly correlated with HR at baseline (Spearman $r=0.14$ and $r=0.22$, respectively). The STAI-Y and VAS scores after the intervention were not correlated with the maximal $\mathrm{HR}_{\text {peak }}$ (Spearman $r=0.02$ and $r=-0.04$, respectively)

\section{Discussion}

\section{Principal Findings}

The unpredictable out-of-hospital environment and high-stake CPR situations lead to major stressful experiences for involved 
rescuers, which can adversely affect patient safety [5]. In this randomized controlled trial, we report a significant increase in both perceived and physiological stress in paramedics during the preparation of emergency drugs for pediatric OHCA patients in a simulated model. However, perceived stress was $27 \%$ lower among those who used a specific mHealth app designed to facilitate drug preparation compared with those who only had access to conventional preparation methods. This result was observed irrespective of paramedics' years of experience, age, or gender, suggesting a worthwhile benefit of its use in the prehospital setting.

Quantification of the acute stress response of rescuers during CPR has been the subject of many studies, although no single stress-specific marker for its measurement has been definitively validated [70]. Thus, previous studies have used, alone or in conjunction, different surrogate stress markers (ie, biological, electrophysiological or psychological) to assess the relationship between stress and CPR performance [11]. Those considering subjective stress markers by means of self-reported questionnaires, such as the STAI, showed the strongest association with lower performance $[6,11]$. On the other hand, stress-coping strategies such as leadership and stress management training, cognitive aids (eg, checklists and algorithms), and mindfulness meditation have been shown to enhance CPR performance [5,71]. However, these studies mostly focused primarily on residents [11], a less experienced and likely more stress-prone population, thus providing little evidence regarding more experienced rescuers. Evidence regarding paramedics is scarce. Few studies in the field have yielded conflicting results. LeBlanc et al [56] compared paramedics' acute perceived and salivary cortisol stress responses and performance during simulated low- and high-stress scenarios. They observed impairments in some aspects of clinical performance in response to a high-stress scenario. Among these aspects, stress significantly impaired drug dosage calculation and was associated with a greater risk of error [14]. Interestingly, these authors reported a subjective mean STAI-rated overall stress of 46.1 for paramedics under high-stress conditions, corroborating our own findings. Conversely, Bjørshol et al [72] observed no performance impairment associated with higher self-reported stress in a randomized trial comparing paramedics under calm CPR conditions with those under stressful CPR conditions. Unfortunately, in these studies, no evaluation of interventions aimed at specifically reducing stress during CPR and studying their consecutive impact on performance was carried out. To date, the bulk of the research and development for interventions to reduce stress has mostly focused on long-lasting mental illnesses using mobile self-management apps in the field of health psychology [73]. To our knowledge, this trial is the first of its kind to report reduced perceived stress during multiple drug dosage calculations by advanced care paramedics supported by a mobile app in acute life-threatening situations. Prehospital dosing errors, although probably underreported due to failure to recognize them or reluctance to report them [70,74], affect approximately 56,000 children treated by EMS each year in the United States, with drugs administered outside of the proper dose range reported in up to $39.8 \%$ of more than 5500 children $[31,75]$. Facilitating emergency drug

preparation at pediatric dosage while reducing stress might reduce these errors.

Acute stress situations elicit not only a psychological but also an adaptive, generally transient, physiological stress response carried out by regulatory pathways through the activation of the cardiovascular, endocrine, immune, and autonomic nervous systems $[76,77]$. The overall stress response is a combination of these complex and relatively independent pathways, without necessarily showing correlations with each other [57,58,78]. Additionally, there are interindividual differences in perceived and physiological stress responses in the same situation [76,78]. In this study, although perceived acute stress was reduced by the use of the app, such a reduction was not observed in HR that remained high in both groups during the scenario. This finding is consistent with that of the existing literature. At the individual level, the relationship between self-reported perceived stress and physiological stress measured by objective parameters such as HR has been shown to be somewhat inconsistent $[57,79]$. Clarke et al [80] examined the relationship between emergency medicine residents' self-reported stress before and after a simulation exercise and HR throughout the scenario. They observed that HR elevation alone correlated poorly with both perceived stress and clinical performance. Similar results were observed in another study where varying stress levels in simulated trauma scenarios elicited higher subjective stress and cortisol levels and poorer performance among residents exposed to high-stress conditions, whereas HR elevation was not significantly different between low- or high-stress conditions [81]. Among the reasons that may explain this phenomenon, it has been speculated that strenuous physical activity could be a confounding factor for HR, limiting its value as a marker of mental stress in acute situations [6,11]. In this study, physical activity was limited to the initial hands-on resuscitation period. Thereafter, physical activity was restricted to the preparation of drugs in close proximity to the patient, thus limiting exertion. Hence, although indicative of a state of mental stress in the absence of physical exertion, it appears from this study that sustained HR at high levels cannot be used alone as a physiological expression of perceived stress. An alternative explanation for the variation in HR observed over the course of the scenario may lie in the level of stress-induced physiological activation desirable for optimal task performance, with higher HR levels observed during drug preparations. This is consistent with the relationship between stress and performance that has been described theoretically by Yerkes-Dodson [82] and follows an inverted U-shaped curve. At low levels of stress, performance is poor but increases with increasing stress levels until a certain optimal point is reached, beyond which task performance and decision making abilities could become impaired, followed by a decline in performance quality [83]. Although we cannot comment on whether the observed HR levels represented the optimal HR zone for best performance, our results suggest that an adaptive physiological response to stress, at least in terms of HR levels, was similarly triggered in both study groups.

\section{Limitations}

This study had several limitations. First, as drug preparation times varied considerably from one participant to another and could have influenced any stress attenuation or exaggeration 
over time, we decided not to measure average HRs per drug. Second, the collection of additional physiological stress markers was not carried out, which could also be seen as a limitation. However, measuring paramedics' cortisol levels would have required complex consideration of intra and interindividual circadian rhythms among day and night shift paramedics, as well as serial collection of blood, saliva, or sweat samples to capture baseline and in-scenario values, making the procedure impractical and potentially prone to preparation bias [84]. On the other hand, measuring paramedics' HR variability, which has been shown to be influenced by stress during emergency care and a reliable means of monitoring it $[11,57,85]$, would require signal acquisition by an electrocardiogram. This could have potentially restrained paramedics' movements and involvement, thus hindering their ability to prepare the drugs according to usual practice. Considering the use of wearable photoplethysmography to measure pulse rate variability may be a promising alternative to overcome this limitation in future studies [86,87]. Another limitation of our trial includes its simulated setting, which raises the concern of its generalizability to real-life situations. High-fidelity simulation has been shown to be as realistic and stressful as real-life situations, both at the psychological and physiological levels $[6,11,88]$. Furthermore, simulation is an essential method for assessing research questions and technologies that cannot be answered during real CPR as the diversity among patients and their diseases makes such studies difficult to standardize in critical situations [89]. In addition, in the voluntary absence of correlational analysis in this study due to a nonexhaustive investigation of all stress response axes, our data does not allow causal inferences to be made about the relationship between psychological and physiological stress reactivity and emergency drugs preparation. They only provide a sketch in this direction, which requires further research. Finally, we acknowledge that this study did not distinguish whether and to what extent emergency drugs preparation had a greater influence on stress than the pediatric OHCA situation itself or vice versa.

\section{Conclusions}

In this nested randomized controlled trial, paramedics confronted with a high-stress pediatric OHCA scenario reported a lower level of perceived stress when using a mobile app designed to help pediatric drug preparation compared with conventional calculation methods. As acute perceived stress is associated with lower CPR performance in calculating drug dosages and as the children are particularly vulnerable to such errors, we suggest that dedicated medical mobile apps have the potential to reduce stress while improving medication safety. This could change the prehospital clinical practice in the area of pediatric emergency medicine. The next step would be to determine in real-life studies whether stress reduction through the app translates into improved clinical outcomes to contrast the results of this actual research.

\section{Acknowledgments}

We are grateful to Rosemary Sudan (Freelance Technical Editor) for providing editorial assistance. We are also grateful to Mr. Lorenz Vogt and Mr. Alexandre Glasner for their assistance in translation in some emergency medical services centers. These 3 people were compensated for their work.

This trial was funded by the Swiss National Science Foundation (grant SNSF_32003B_182374. The funders had no role in the design and conduct of the study; collection, management, analysis, and interpretation of the data; preparation, review, or approval of the manuscript; and decision to submit the manuscript for publication.

\section{Authors' Contributions}

ML was responsible for the literature search and reading the articles, performed data curing, interpreted the data, and drafted the manuscript together with JNS. LB, SM, and JNS were responsible for the concept and design of the study and critical review of the manuscript content, with the support of CC, LS, and FR. LB, SM, and JNS were responsible for the data acquisition. CC performed the data analyses. KH and FH provided technical and material support. FE was responsible for the development of the project software with the support of SM and JNS. CL and AG oversaw the development of the project software. SM was the trial coordinator and procured funding. JNS was responsible for the overall conduct of this study and oversaw the writing of this manuscript. All authors have contributed to, seen, and approved the final submitted version of the manuscript; had full access to all the data, including statistical reports and tables in the study, and take responsibility for the integrity of the data and the accuracy of the data analysis. The corresponding author (JNS) confirms that he had full access to the participants' data and endorsed the final responsibility for the submission. He further affirms that the manuscript is an honest, accurate, and transparent account of the study being reported; that no important aspects of the study have been omitted, and that any deviations from the study plan have been explained. The collaborating members of the PedAMINES Prehospital Group are as follows (for the complete list of the group members, see Multimedia Appendix 2): Marec Saillant, EMS-p (Geneva Team Ambulances (GTA), Geneva, Switzerland), Renaud Grandjean EMS-p (SK Ambulances, Geneva, Switzerland), Annick Leuenberger EMS-p (Secours Ambulances Genève (SAG), Geneva, Switzerland), Pascal Donnet, EMS-p, and Philippe Hauck, EMS-p (Service de Sauvetage et de Lutte contre les Incendies Aéroportuaires (SSLIA), Geneva, Switzerland), Sébastien Pappalardo EMS-p (Service d'Incendie et de Secours (SIS), Geneva, Switzerland), Philippe Nidegger EMS-p (Ambulance Riviera, La Tour-de-Peilz, Switzerland), David Neel, Flight EMS-p (Air Zermatt SA, Zermatt, Switzerland), Stephan Steinhauser, MD (Höhere Fachschule für Rettungsberufe (HFRB), Zürich, Switzerland), Michel Ceschi, EMS-p, and Bruno Belli EMS-p (Servizio Ambulanza Locarnese e Valli (SALVA), Ticino, Switzerland), Sébastien Ottet EMS-p, and Wenceslao Garcia, MD (Ambulances du Sud Fribourgeois, Vaulruz, Switzerland), 
Yoan Mollier EMS-p, Yves Vollenweider EMS-p, and Pierre Voumard, EMS-p (Service Communal de la Sécurité (SCS), Neuchâtel, Switzerland), Karine Corbat, EMS-p, and Philippe Robadey, EMS-p (Service de Protection et Sauvetage Lausanne (SPSL), Lausanne, Switzerland), Joël Bauer, EMS-p, and Cyril Berger, EMS-p (Centre de Secours et d'Urgences (CSU) Morges-Aubonne, Aubonne, Switzerland). These contributors coordinated the trial in their respective EMS centers. None of them received compensation for their role in the study.

\section{Conflicts of Interest}

Geneva University Hospitals are owners of the PedAMINES app. The app is currently commercially available on Google Play Store and App Store (Apple) for research and educational purposes. JNS, CL, AG, FE, and SM declare individual intellectual property rights on this app and, as employees of Geneva University Hospitals, indirect institutional rewarding through its commercialization (ie, without personal enrichment). The authors declare no other relationships or activities that could appear to have influenced the submitted work. All authors have completed the International Committee of Medical Journal Editors uniform disclosure form and declare no support from commercial entities for the submitted work, and no financial relationships with any commercial entities that might have an interest in the submitted work in the previous 3 years.

\section{Multimedia Appendix 1}

Subgroup analysis for the primary outcome by gender, age, and years since paramedic certification and State-Trait Anxiety Inventory perceived stress score.

[DOCX File, 17 KB-Multimedia Appendix 1]

\section{Multimedia Appendix 2}

PedAMINES Prehospital Trial Group.

[DOCX File, 16 KB-Multimedia Appendix 2]

\section{References}

1. Virani SS, Alonso A, Benjamin EJ, Bittencourt MS, Callaway CW, Carson AP, American Heart Association Council on Epidemiology and Prevention Statistics Committee and Stroke Statistics Subcommittee. Heart Disease and Stroke Statistics-2020 Update: A report from the American Heart Association. Circulation 2020 Mar 03;141(9):139-596. [doi: 10.1161/CIR.0000000000000757] [Medline: 31992061]

2. Yan S, Gan Y, Jiang N, Wang R, Chen Y, Luo Z, et al. The global survival rate among adult out-of-hospital cardiac arrest patients who received cardiopulmonary resuscitation: a systematic review and meta-analysis. Crit Care 2020 Feb 22;24(1):61 [FREE Full text] [doi: 10.1186/s13054-020-2773-2] [Medline: 32087741]

3. Genbrugge C, Eertmans W, Salcido DD. Monitor the quality of cardiopulmonary resuscitation in 2020. Curr Opin Crit Care 2020 Jun;26(3):219-227. [doi: 10.1097/MCC.0000000000000726] [Medline: 32332284]

4. Krage R, Zwaan L, Len LT, Kolenbrander MW, van Groeningen D, Loer SA, et al. Relationship between non-technical skills and technical performance during cardiopulmonary resuscitation: does stress have an influence? Emerg Med J 2017 Nov;34(11):728-733 [FREE Full text] [doi: 10.1136/emermed-2016-205754] [Medline: 28844039]

5. Groombridge CJ, Kim Y, Maini A, Smit DV, Fitzgerald MC. Stress and decision-making in resuscitation: A systematic review. Resuscitation 2019 Nov;144:115-122 [FREE Full text] [doi: 10.1016/j.resuscitation.2019.09.023] [Medline: 31562904]

6. Hunziker S, Semmer NK, Tschan F, Schuetz P, Mueller B, Marsch S. Dynamics and association of different acute stress markers with performance during a simulated resuscitation. Resuscitation 2012 May;83(5):572-578. [doi: 10.1016/j.resuscitation.2011.11.013] [Medline: 22115935]

7. Hunziker S, Laschinger L, Portmann-Schwarz S, Semmer NK, Tschan F, Marsch S. Perceived stress and team performance during a simulated resuscitation. Intensive Care Med 2011 Sep;37(9):1473-1479. [doi: 10.1007/s00134-011-2277-2] [Medline: 21695475]

8. Keitel A, Ringleb M, Schwartges I, Weik U, Picker O, Stockhorst U, et al. Endocrine and psychological stress responses in a simulated emergency situation. Psychoneuroendocrinology 2011 Jan;36(1):98-108. [doi: 10.1016/j.psyneuen.2010.06.011] [Medline: 20650570]

9. Cumming S, Harris L. The impact of anxiety on the accuracy of diagnostic decision-making. Stress Health 2001 Oct 27;17(5):281-286 [FREE Full text] [doi: 10.1002/smi.909]

10. Schull MJ, Ferris LE, Tu JV, Hux JE, Redelmeier DA. Problems for clinical judgement: 3 . Thinking clearly in an emergency. Can Med Asso J 2001 Apr 17;164(8):1170-1175 [FREE Full text] [Medline: 11338805]

11. Vincent A, Semmer NK, Becker C, Beck K, Tschan F, Bobst C, et al. Does stress influence the performance of cardiopulmonary resuscitation? A narrative review of the literature. J Crit Care 2021 Jun;63:223-230. [doi: 10.1016/j.jcrc.2020.09.020] [Medline: 33046274] 
12. Lauria MJ, Gallo IA, Rush S, Brooks J, Spiegel R, Weingart SD. Psychological skills to improve emergency care providers' performance under stress. Ann Emerg Med 2017 Dec;70(6):884-890. [doi: 10.1016/j.annemergmed.2017.03.018] [Medline: 28460863]

13. Dias R, Neto A. Stress levels during emergency care: A comparison between reality and simulated scenarios. J Crit Care 2016 Jun;33:8-13. [doi: 10.1016/j.jcrc.2016.02.010] [Medline: 26987261]

14. LeBlanc VR, MacDonald RD, McArthur B, King K, Lepine T. Paramedic performance in calculating drug dosages following stressful scenarios in a human patient simulator. Prehosp Emerg Care 2005;9(4):439-444. [doi: 10.1080/10903120500255255] [Medline: 16263679]

15. Brindley PG, O'Dochartaigh D, Volney C, Ryan S, Douma MJ. Time delays associated with vasoactive medication preparation and delivery in simulated patients at risk of cardiac arrest. J Crit Care 2017 Aug;40:149-153. [doi: 10.1016/j.jcrc.2017.04.003] [Medline: 28402925]

16. Flannery AH, Parli SE. Medication errors in cardiopulmonary arrest and code-related situations. Am J Crit Care 2016 Jan;25(1):12-20. [doi: 10.4037/ajcc2016190] [Medline: 26724288]

17. Kaufmann J, Laschat M, Wappler F. Medication errors in pediatric emergencies: a systematic analysis. Dtsch Arztebl Int 2012 Sep;109(38):609-616 [FREE Full text] [doi: 10.3238/arztebl.2012.0609] [Medline: 23093991]

18. Moreira ME, Hernandez C, Stevens AD, Jones S, Sande M, Blumen JR, et al. Color-coded prefilled medication syringes decrease time to delivery and dosing error in simulated emergency department pediatric resuscitations. Ann Emerg Med 2015 Aug;66(2):97-106 [FREE Full text] [doi: 10.1016/j.annemergmed.2014.12.035] [Medline: 25701295]

19. McDowell SE, Ferner HS, Ferner RE. The pathophysiology of medication errors: how and where they arise. Br J Clin Pharmacol 2009 Jun;67(6):605-613 [FREE Full text] [doi: 10.1111/j.1365-2125.2009.03416.x] [Medline: 19594527]

20. Stucky ER, American Academy of Pediatrics Committee on Drugs, American Academy of Pediatrics Committee on Hospital Care. Prevention of medication errors in the pediatric inpatient setting. Pediatrics 2003 Aug;112(2):431-436. [doi: 10.1542/peds.112.2.431] [Medline: 12897304]

21. Cushman JT, Fairbanks RJ, O'Gara KG, Crittenden CN, Pennington EC, Wilson MA, et al. Ambulance personnel perceptions of near misses and adverse events in pediatric patients. Prehosp Emerg Care 2010;14(4):477-484 [FREE Full text] [doi: 10.3109/10903127.2010.497901] [Medline: 20662679]

22. Luten R, Wears RL, Broselow J, Croskerry P, Joseph MM, Frush K. Managing the unique size-related issues of pediatric resuscitation: reducing cognitive load with resuscitation aids. Acad Emerg Med 2002 Aug;9(8):840-847 [FREE Full text] [Medline: 12153892]

23. Seidel JS, Henderson DP, Ward P, Wayland BW, Ness B. Pediatric prehospital care in urban and rural areas. Pediatrics 1991 Oct;88(4):681-690. [Medline: 1896270]

24. Kaji AH, Gausche-Hill M, Conrad H, Young KD, Koenig WJ, Dorsey E, et al. Emergency medical services system changes reduce pediatric epinephrine dosing errors in the prehospital setting. Pediatrics 2006 Oct;118(4):1493-1500. [doi: 10.1542/peds.2006-0854] [Medline: 17015540]

25. Shah MN, Cushman JT, Davis CO, Bazarian JJ, Auinger P, Friedman B. The epidemiology of emergency medical services use by children: an analysis of the National Hospital Ambulatory Medical Care Survey. Prehosp Emerg Care 2008;12(3):269-276 [FREE Full text] [doi: 10.1080/10903120802100167] [Medline: 18584491]

26. Su E, Schmidt TA, Mann NC, Zechnich AD. A randomized controlled trial to assess decay in acquired knowledge among paramedics completing a pediatric resuscitation course. Acad Emerg Med 2000 Jul;7(7):779-786 [FREE Full text] [doi: 10.1111/j.1553-2712.2000.tb02270.x] [Medline: 10917328]

27. Benjamin L, Frush K, Shaw K, Shook JE, Snow SK. Pediatric medication safety in the emergency department. Pediatrics 2018 Mar 01;141(3):e20174066. [doi: 10.1542/peds.2017-4066]

28. Gonzales K. Medication administration errors and the pediatric population: a systematic search of the literature. J Pediatr Nurs 2010 Dec;25(6):555-565. [doi: 10.1016/j.pedn.2010.04.002] [Medline: 21035020]

29. Kaushal R, Bates DW, Landrigan C, McKenna KJ, Clapp MD, Federico F, et al. Medication errors and adverse drug events in pediatric inpatients. J Am Med Assoc 2001 Apr 25;285(16):2114-2120. [Medline: 11311101]

30. Marcin JP, Dharmar M, Cho M, Seifert LL, Cook JL, Cole SL, et al. Medication errors among acutely ill and injured children treated in rural emergency departments. Ann Emerg Med 2007 Oct;50(4):361-367. [doi: 10.1016/j.annemergmed.2007.01.020] [Medline: 17433496]

31. Hoyle JD, Crowe RP, Bentley MA, Beltran G, Fales W. Pediatric prehospital medication dosing errors: a national survey of paramedics. Prehosp Emerg Care 2017;21(2):185-191. [doi: 10.1080/10903127.2016.1227001] [Medline: 28257249]

32. Lammers R, Byrwa M, Fales W. Root causes of errors in a simulated prehospital pediatric emergency. Acad Emerg Med 2012 Jan;19(1):37-47 [FREE Full text] [doi: 10.1111/j.1553-2712.2011.01252.x] [Medline: 22251191]

33. Hall C, Robertson D, Rolfe M, Pascoe S, Passey ME, Pit SW. Do cognitive aids reduce error rates in resuscitation team performance? Trial of emergency medicine protocols in simulation training (TEMPIST) in Australia. Hum Resour Health 2020 Jan 08;18(1):1 [FREE Full text] [doi: 10.1186/s12960-019-0441-x] [Medline: $\underline{31915029}$ ]

34. Gausche-Hill M, Krug S, Wright J. Emergency medical services (EMS) 2050: a vision for the future of pediatric prehospital care. Prehosp Emerg Care 2021;25(1):91-94. [doi: 10.1080/10903127.2020.1734123] [Medline: 32091291] 
35. Roncero A, Marques G, Sainz-De-Abajo B, Martín-Rodríguez F, Vegas C, Garcia-Zapirain B, et al. Mobile health apps for medical emergencies: systematic review. JMIR Mhealth Uhealth 2020 Dec 11;8(12):e18513 [FREE Full text] [doi: 10.2196/18513] [Medline: 33306037]

36. Siebert JN, Ehrler F, Combescure C, Lacroix L, Haddad K, Sanchez O, et al. A mobile device app to reduce time to drug delivery and medication errors during simulated pediatric cardiopulmonary resuscitation: a randomized controlled trial. $\mathrm{J}$ Med Internet Res 2017 Feb 01;19(2):e31 [FREE Full text] [doi: 10.2196/jmir.7005] [Medline: 28148473]

37. Siebert JN, Ehrler F, Combescure C, Lovis C, Haddad K, Hugon F, PedAMINES Trial Group. A mobile device application to reduce medication errors and time to drug delivery during simulated paediatric cardiopulmonary resuscitation: a multicentre, randomised, controlled, crossover trial. Lancet Child Adolesc Health 2019 May;3(5):303-311. [doi: 10.1016/S2352-4642(19)30003-3] [Medline: 30797722]

38. Siebert JN, Bloudeau L, Combescure CB, Haddad K, Hugon F, Suppan L, Pediatric Accurate Medication in Emergency Situations (PedAMINES) Prehospital Group. Effect of a mobile app on prehospital medication errors during simulated pediatric resuscitation: a randomized clinical trial. JAMA Netw Open 2021 Aug 02;4(8):e2123007 [FREE Full text] [doi: 10.1001/jamanetworkopen.2021.23007] [Medline: $\underline{\text { 34459905] }}$

39. Siebert JN, Bloudeau L, Ehrler F, Combescure C, Haddad K, Hugon F, et al. A mobile device app to reduce prehospital medication errors and time to drug preparation and delivery by emergency medical services during simulated pediatric cardiopulmonary resuscitation: study protocol of a multicenter, prospective, randomized controlled trial. Trials 2019 Nov 20;20(1):634 [FRE Full text] [doi: 10.1186/s13063-019-3726-4] [Medline: 31747951]

40. Stenner K, van Even S, Collen A. Early adopters of paramedic prescribing: a qualitative study. Br Paramed J 2019 Dec 01;4(3):57 [FREE Full text] [doi: 10.29045/14784726.2019.12.4.3.57] [Medline: $\underline{33447155]}$

41. Kiguchi T, Okubo M, Nishiyama C, Maconochie I, Ong ME, Kern KB, et al. Out-of-hospital cardiac arrest across the World: First report from the International Liaison Committee on Resuscitation (ILCOR). Resuscitation 2020 Jul;152:39-49. [doi: 10.1016/j.resuscitation.2020.02.044] [Medline: 32272235]

42. Ehrler F, Siebert JN. PedAMINES: a disruptive mHealth app to tackle paediatric medication errors. Swiss Med Wkly 2020 Aug 24;150:w20335 [FREE Full text] [doi: 10.4414/smw.2020.20335] [Medline: 32920794]

43. Oviatt S. Human-centered design meets cognitive load theory: designing interfaces that help people think. In: Proceedings of the 14th ACM international conference on Multimedia. New York, NY, United States: Association for Computing Machinery; 2006 Oct 23 Presented at: MM '06: 14th ACM international conference on Multimedia; October 23 - 27, 2006 ; Santa Barbara, CA, USA p. 871-880. [doi: 10.1145/1180639.1180831]

44. Durrani S, Durrani Q. Applying cognitive psychology to user interfaces. In: Proceedings of the First International Conference on Intelligent Human Computer Interaction. New Delhi: Springer India; 2009 Presented at: First International Conference on Intelligent Human Computer Interaction; January 20-23, 2009; Allahabad, India p. 156-168.

45. Harper S, Michailidou E, Stevens R. Toward a definition of visual complexity as an implicit measure of cognitive load. ACM Trans Appl Percept 2009 Feb 15;6(2):1-18. [doi: 10.1145/1498700.1498704]

46. MacKenzie IS. Fitts' law as a research and design tool in human-computer interaction. Hum Comput Interact 2009 Nov 11;7(1):91-139. [doi: $10.1207 / \mathrm{s} 15327051 \mathrm{hci0701} 3$ ]

47. Spillers F. Progressive disclosure: the glossary of human computer interaction. Denmark: Interaction Design Foundation. 2016. URL: https://www.interaction-design.org/literature/book/the-glossary-of-human-computer-interaction/ progressive-disclosure [accessed 2021-09-19]

48. Venkatesh V, Morris MG, Davis GB, Davis FD. User acceptance of information technology: toward a unified view. MIS Q 2003;27(3):425. [doi: 10.2307/30036540]

49. Brooke J. SUS- 'A quick and dirty' usability scale. In: Usability Evaluation in Industry. London, UK: Taylor and Francis; 1996:4-7.

50. Sousa VE, Lopez KD. Towards usable e-Health. A systematic review of usability questionnaires. Appl Clin Inform 2017 Dec 10;8(2):470-490 [FREE Full text] [doi: 10.4338/ACI-2016-10-R-0170] [Medline: 28487932]

51. Gauthier J, Bouchard S. Adaptation canadienne-française de la forme révisée du State-Trait Anxiety Inventory de Spielberger. Can J Behav Sci / Revue canadienne des sciences du comportement 1993 Oct;25(4):559-578. [doi: 10.1037/h0078881]

52. Spielberger CD. State-trait anxiety inventory for adults ${ }^{\mathrm{TM}}$. Mind Garden, Inc. URL: http://www.mindgarden.com/products/ staisad.htm [accessed 2021-09-19]

53. Spielberger CD. Manual for the State-Trait Anxiety Inventory STAI (form Y) ("self-evaluation questionnaire"). Palo Alto, CA, USA: Consulting Psychologists Press; 1983.

54. Spielberger C, Gorsuch R, Lushene R, Vagg P, Jacobs G. State-trait anxiety inventory for adults: self-evaluation questionnaire (STAI Form Y-1 and Form Y-2). Mind Garden, Redwood City, CA. 1968. URL: https://oml.eular.org/sysModules/obxOml/ docs/ID 150/State-Trait-Anxiety-Inventory.pdf [accessed 2021-09-22]

55. Harvey A, Nathens AB, Bandiera G, Leblanc VR. Threat and challenge: cognitive appraisal and stress responses in simulated trauma resuscitations. Med Educ 2010 Jun;44(6):587-594. [doi: 10.1111/j.1365-2923.2010.03634.x] [Medline: 20604855]

56. Leblanc VR, Regehr C, Tavares W, Scott AK, Macdonald R, King K. The impact of stress on paramedic performance during simulated critical events. Prehosp Disaster Med 2012 Aug;27(4):369-374. [doi: 10.1017/S1049023X12001021] [Medline: 22831965] 
57. Ghazali DA, Darmian-Rafei I, Nadolny J, Sosner P, Ragot S, Oriot D. Evaluation of stress response using psychological, biological, and electrophysiological markers during immersive simulation of life threatening events in multidisciplinary teams. Aust Crit Care 2018 Jul;31(4):226-233. [doi: 10.1016/j.aucc.2017.07.001] [Medline: 28756943]

58. Bong C, Fraser K, Oriot D. Cognitive load and stress in simulation. In: Grant V, Cheng A, editors. Comprehensive Healthcare Simulation: Pediatrics. Cham: Springer International Publishing; Jun 16, 2016:3-17.

59. Spielberger C, Gorsuch R, Lushene R, Vagg R, Jacobs G. State-Trait Anxiety Inventory for Adults. Manual, Instrument, and Scoring Guide. Redwood City, CA, USA: Mind Garden, Inc; 1983.

60. Lesage F, Berjot S, Deschamps F. Clinical stress assessment using a visual analogue scale. Occup Med (Lond) 2012 Dec;62(8):600-605 [FREE Full text] [doi: 10.1093/occmed/kqs140] [Medline: 22965867]

61. Furedy JJ, Szabo A, Péronnet F. Effects of psychological and physiological challenges on heart rate, T-wave amplitude, and pulse-transit time. Int J Psychophysiol 1996;22(3):173-183. [doi: 10.1016/0167-8760(96)00025-6] [Medline: 8835625]

62. Rider BC, Conger SA, Ditzenberger GL, Besteman SS, Bouret CM, Coughlin AM. Examining the accuracy of the Polar A360 Monitor. J Strength Cond Res 2021 Aug 01;35(8):2165-2169. [doi: 10.1519/JSC.0000000000003136] [Medline: $\underline{34398076]}$

63. Boudreaux BD, Hebert EP, Hollander DB, Williams BM, Cormier CL, Naquin MR, et al. Validity of wearable activity monitors during cycling and resistance exercise. Med Sci Sports Exerc 2018 Mar;50(3):624-633. [doi:

10.1249/MSS.0000000000001471] [Medline: 29189666]

64. Baldwin S, Bennell C, Andersen JP, Semple T, Jenkins B. Stress-activity mapping: physiological responses during general duty police encounters. Front Psychol 2019;10:2216 [FREE Full text] [doi: 10.3389/fpsyg.2019.02216] [Medline: 31636582]

65. Bates D, Mächler M, Bolker B, Walker S. Fitting linear mixed-effects models using lme4. J Stat Soft 2015;67(1):1-48. [doi: $10.18637 /$ jss.v067.i01]

66. World Medical Association. World Medical Association Declaration of Helsinki: ethical principles for medical research involving human subjects. J Am Med Assoc 2013 Nov 27;310(20):2191-2194. [doi: 10.1001/jama.2013.281053] [Medline: 24141714]

67. International Conference on Harmonisation E9 Expert Working Group. ICH Harmonised Tripartite Guideline. Statistical principles for clinical trials. Stat Med 1999 Aug 15;18(15):1905-1942. [Medline: 10532877]

68. Eysenbach G, CONSORT-EHEALTH Group. CONSORT-EHEALTH: improving and standardizing evaluation reports of Web-based and mobile health interventions. J Med Internet Res 2011;13(4):e126 [FREE Full text] [doi: 10.2196/jmir.1923] [Medline: 22209829]

69. Cheng A, Kessler D, Mackinnon R, Chang TP, Nadkarni VM, Hunt EA, International Network for Simulation-based Pediatric Innovation, Research,Education (INSPIRE) Reporting Guidelines Investigators. Reporting guidelines for health care simulation research: extensions to the CONSORT and STROBE statements. Simul Healthc 2016 Aug;11(4):238-248. [doi: 10.1097/SIH.0000000000000150] [Medline: 27465839]

70. Ramadanov N, Klein R, Schumann U, Aguilar AD, Behringer W. Factors, influencing medication errors in prehospital care: a retrospective observational study. Medicine (Baltimore) 2019 Dec;98(49):e18200 [FREE Full text] [doi: 10.1097/MD.0000000000018200] [Medline: 31804342]

71. Hunziker S, Pagani S, Fasler K, Tschan F, Semmer NK, Marsch S. Impact of a stress coping strategy on perceived stress levels and performance during a simulated cardiopulmonary resuscitation: a randomized controlled trial. BMC Emerg Med 2013 Apr 22;13(8):1-9 [FREE Full text] [doi: 10.1186/1471-227X-13-8] [Medline: 23607331]

72. Bjørshol CA, Myklebust H, Nilsen KL, Hoff T, Bjørkli C, Illguth E, et al. Effect of socioemotional stress on the quality of cardiopulmonary resuscitation during advanced life support in a randomized manikin study. Crit Care Med 2011 Feb;39(2):300-304. [doi: 10.1097/CCM.0b013e3181ffe100] [Medline: 21076285]

73. Martín D, De La Torre I, Garcia-Zapirain B, Lopez-Coronado M, Rodrigues J. Managing and controlling stress using mHealth: systematic search in App stores. JMIR Mhealth Uhealth 2018 May 09;6(5):e111 [FREE Full text] [doi: 10.2196/mhealth.8866] [Medline: 29743152]

74. Walker D, Moloney C, SueSee B, Sharples R. Contributing factors that influence medication errors in the prehospital paramedic environment: a mixed-method systematic review protocol. BMJ Open 2019 Dec 23;9(12):e034094 [FREE Full text] [doi: 10.1136/bmjopen-2019-034094] [Medline: $\underline{\text { 31874897] }}$

75. Hoyle JD, Davis AT, Putman KK, Trytko JA, Fales WD. Medication dosing errors in pediatric patients treated by emergency medical services. Prehosp Emerg Care 2012;16(1):59-66. [doi: 10.3109/10903127.2011.614043] [Medline: 21999707]

76. Schneiderman N, Ironson G, Siegel SD. Stress and health: psychological, behavioral, and biological determinants. Annu Rev Clin Psychol 2005;1:607-628 [FREE Full text] [doi: 10.1146/annurev.clinpsy.1.102803.144141] [Medline: 17716101]

77. Epel E, Crosswell A, Mayer S, Prather A, Slavich G, Puterman E, et al. More than a feeling: a unified view of stress measurement for population science. Front Neuroendocrinol 2018 Apr;49:146-169 [FREE Full text] [doi: 10.1016/j.yfrne.2018.03.001] [Medline: 29551356]

78. Can YS, Chalabianloo N, Ekiz D, Ersoy C. Continuous stress detection using wearable sensors in real life: algorithmic programming contest case study. Sensors 2019 Apr 18;19(8):1849. [doi: 10.3390/s19081849] 
79. Oldehinkel AJ, Ormel J, Bosch NM, Bouma EM, Van Roon AM, Rosmalen JG, et al. Stressed out? Associations between perceived and physiological stress responses in adolescents: the TRAILS study. Psychophysiology 2011 Apr;48(4):441-452. [doi: 10.1111/j.1469-8986.2010.01118.x] [Medline: 21361964]

80. Clarke S, Horeczko T, Cotton D, Bair A. Heart rate, anxiety and performance of residents during a simulated critical clinical encounter: a pilot study. BMC Med Educ 2014 Jul 27;14:153 [FREE Full text] [doi: 10.1186/1472-6920-14-153] [Medline: 25064689]

81. Harvey A, Bandiera G, Nathens AB, LeBlanc VR. Impact of stress on resident performance in simulated trauma scenarios. J Trauma Acute Care Surg 2012 Feb;72(2):497-503. [doi: 10.1097/ta.0b013e31821f84be] [Medline: 22439221]

82. Yerkes RM, Dodson JD. The relation of strength of stimulus to rapidity of habit-formation. J Comp Neurol Psychol 1908 Nov;18(5):459-482. [doi: 10.1002/cne.920180503]

83. Frazier SE, Parker SH. Measurement of physiological responses to acute stress in multiple occupations: a systematic review and implications for front line healthcare providers. Transl Behav Med 2019 Jan 01;9(1):158-166. [doi: 10.1093/tbm/iby019] [Medline: 29522140]

84. Zamkah A, Hui T, Andrews S, Dey N, Shi F, Sherratt RS. Identification of suitable biomarkers for stress and emotion detection for future personal affective wearable sensors. Biosensors (Basel) 2020 Apr 16;10(4):40 [REE Full text] [doi: 10.3390/bios10040040] [Medline: 32316280]

85. Kim H, Cheon E, Bai D, Lee YH, Koo B. Stress and heart rate variability: a meta-analysis and review of the literature. Psychiatry Investig 2018 Mar;15(3):235-245 [FREE Full text] [doi: 10.30773/pi.2017.08.17] [Medline: 29486547]

86. Mejía-Mejía E, Budidha K, Abay TY, May JM, Kyriacou PA. Heart rate variability (HRV) and pulse rate variability (PRV) for the assessment of autonomic responses. Front Physiol 2020;11:779 [FREE Full text] [doi: 10.3389/fphys.2020.00779] [Medline: $\underline{\text { 32792970] }}$

87. Pinheiro N, Couceiro R, Henriques J, Muehlsteff J, Quintal I, Goncalves L, et al. Can PPG be used for HRV analysis? Conf Proc IEEE Eng Med Biol Soc 2016 Dec;2016:2945-2949. [doi: 10.1109/EMBC.2016.7591347] [Medline: 28268930]

88. Ghazali DA, Breque C, Sosner P, Lesbordes M, Chavagnat J, Ragot S, et al. Stress response in the daily lives of simulation repeaters. A randomized controlled trial assessing stress evolution over one year of repetitive immersive simulations. PLoS One 2019;14(7):e0220111 [FREE Full text] [doi: 10.1371/journal.pone.0220111] [Medline: $\underline{31344077]}$

89. Cheng A, Auerbach M, Hunt EA, Chang TP, Pusic M, Nadkarni V, et al. Designing and conducting simulation-based research. Pediatrics 2014 Jun;133(6):1091-1101. [doi: 10.1542/peds.2013-3267] [Medline: 24819576]

\author{
Abbreviations \\ CPR: cardiopulmonary resuscitation \\ EMS: emergency medical services \\ mHealth: mobile health \\ OHCA: out-of-hospital cardiac arrest \\ PedAMINES: Pediatric Accurate Medication in Emergency Situations \\ STAI: State-Trait Anxiety Inventory \\ VAS: visual analogue scale
}

Edited by G Eysenbach; submitted 02.07.21; peer-reviewed by A Benis, Y Kim, B Nievas Soriano; comments to author 23.07.21;
revised version received 05.08.21; accepted 08.08.21; published 07.10.21
Please cite as:
Lacour M, Bloudeau L, Combescure C, Haddad K, Hugon F, Suppan L, Rodieux F, Lovis C, Gervaix A, Ehrler F, Manzano S, Siebert
JN, PedAMINES Prehospital Group
Impact of a Mobile App on Paramedics' Perceived and Physiologic Stress Response During Simulated Prehospital Pediatric
Cardiopulmonary Resuscitation: Study Nested Within a Multicenter Randomized Controlled Trial
JMIR Mhealth Uhealth 2021;9(10):e31748
URL: $\underline{\text { https:///mhealth.jmir.org/2021/10/e31748 }}$
doi: $10.2196 / 31748$
PMID: $\underline{34617916}$

CMatthieu Lacour, Laurie Bloudeau, Christophe Combescure, Kevin Haddad, Florence Hugon, Laurent Suppan, Frédérique Rodieux, Christian Lovis, Alain Gervaix, Frédéric Ehrler, Sergio Manzano, Johan N Siebert, PedAMINES Prehospital Group. Originally published in JMIR mHealth and uHealth (https://mhealth.jmir.org), 07.10.2021. This is an open-access article distributed under the terms of the Creative Commons Attribution License (https://creativecommons.org/licenses/by/4.0/), which permits unrestricted use, distribution, and reproduction in any medium, provided the original work, first published in JMIR mHealth and 
uHealth, is properly cited. The complete bibliographic information, a link to the original publication on https://mhealth.jmir.org/, as well as this copyright and license information must be included. 